\title{
Ocorrência de Anadenanthera colubrina (Vell.) Brenan (angico) no semiárido da Paraíba, Nordeste do Brasil
}

\section{Maria da Glória Vieira Anselmo, Ezequiel da Costa Ferreira, Thamires Kelly Nunes Carvalho, Mariana Muniz Nunes, Andrea Maia Fernandes de Araújo Fonseca, Camilla Marques de Lucena, Jacob da Silva Souto e Reinaldo Farias Paiva de Lucena}

Universidade Federal da Paraíba. Centro de Ciências Exatas e da Natureza. Departamento de Sistemática e Ecologia. Laboratório de Etnobiologia e Ciências Ambientais. Cidade Universitária, S/No. João Pessoa-PB, Brasil (CEP 58051-900). *Email: reinadolucena.dr@gmail.com.

Resumo. A presente pesquisa objetivou registrar e analisar a distribuição e disponibilidade de Anadenanthera colubrina (Vell.) Brenan em oito comunidades rurais no semiárido da Paraíba. Foram realizados levantamentos registrando todos os indivíduos com diâmetro no nível do solo (DNS) igual ou superior a $3 \mathrm{~cm}$, utilizando os métodos de coletas das parcelas, ponto quadrante e caminhamento livre. Nos parâmetros fitossociológicos para o método de parcelas registrou-se DeR de 0,04 a 4,2, FrR de 0,21 a 9,33, e VI de 0,27 a 36,18, com exceção da Comunidade Pau d'Arco (Município de Itaporanga), onde não ocorreu registro de nenhum indivíduo. Para o método de ponto quadrante, o DeR foi de 1,8, FrR de 3,01, e VI de 14,62 na Comunidade Santa Rita (Município do Congo), enquanto na Comunidade Coelho (Município de Remígio) não houve registro. No caminhamento livre foi possível identificar o angico em todas as comunidades estudadas, totalizando 694 indivíduos, e na maioria das comunidades os indivíduos localizam-se distantes dos núcleos domiciliares, estando presente em áreas de mata de Caatinga. Os resultados do presente estudo evidenciam a necessidade da implementação de medidas que avaliem os impactos causados pela utilização desta espécie, tendo em vista o seu baixo registro nas comunidades estudadas, principalmente nas áreas antropizadas, o que pode demonstrar que as populações não apresentam atitudes conservacionistas com o angico.

Palavras-chave: Caatinga; Fitossociologia; Conservação.

Abstract. Occurrence of Anadenanthera colubrina (Vell.) Brenan (angico) in the semiarid region of Paraíba, Northeast Brazil. This study aimed to record and analyze the distribution and availability of Anadenanthera colubrina (Vell.) Brenan in eight
Recebido

$29 / 09 / 2020$

Aceito

$26 / 10 / 2020$

Disponível on line

$27 / 10 / 2020$

Publicado

$31 / 12 / 2020$

Acesso aberto

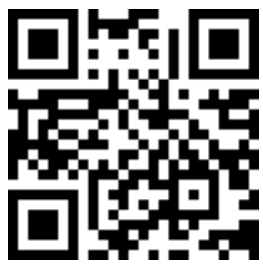

ORCID

다 0000-0003-4763-3457 Maria da Glória Vieira Anselmo

D $0000-0003-4758-7171$

Ezequiel da Costa

Ferreira

ISSN 2359-1412/RBGAS-2020-0147/2020/7/17/13/1215

Rev. Bras. Gest. Amb. Sustent.

http://revista.ecogestaobrasil.net 
rural communities in the semi-arid region of Paraíba. All specimens with a diameter at ground level (DNS) $\geq 3 \mathrm{~cm}$ were recorded, using the plot, point quarter, and free walking methods. Regarding the phytosociological parameters for the plot method, we recorded relative density (DeR) from 0.04 to 4.2 , relative frequency (FrR) from 0.21 to 9.33, and importance value (VI) from 0.27 to 36.18, except for the Community of Pau d'Arco, (Municipality of Itaporanga), where no specimen was recorded. For the point quarter method, DeR was 1.8, FrR was 3.01, and VI was 14.62 in the Community of Santa Rita (Municipality of Congo), whereas no specimen was recorded in the community of Coelho (Municipality of Remígio). In the free walking, A. colubrina could be identified in all study communities, totaling 694 specimens, which in most communities were found far from the residences, occurring in areas of Caatinga. The results presented here show the need to implement measures to assess the impacts caused by the use of A. colubrina, given the low number of specimens recorded in the study communities, especially in anthropized areas, which may indicate the people have no conservation attitudes towards this species.

Keywords: Caatinga, Phytosociology; Conservation.
() $0000-0003-3847-1249$

Thamires Kelly Nunes

Carvalho

(1) 0000-0002-9794-124X

Mariana Muniz Nunes

(1) 0000-0002-2235-5799

Andrea Maia

Fernandes de Araújo

Fonseca

D) 0000-0002-5126-8969

Camilla Marques de

Lucena

(ㄱ) $0000-0002-9787-8623$

Jacob da Silva Souto

D) 0000-0003-4775-7775

Reinaldo Farias Paiva

de Lucena

\section{Introdução}

Em um ecossistema fragmentado, as espécies vegetais são as mais susceptíveis às mudanças climáticas por ocorrer redução no fluxo gênico, diminuição da variabilidade genética e menor probabilidade de recolonização (Dorneles et al., 2013). Já em ambientes protegidos ecologicamente estes efeitos podem ser minimizados, sem maiores danos as espécies (Siqueira et al., 2009).

0 desmatamento oriundo de sucessivos processos exploratórios vem ocasionando a fragmentação dos habitats naturais em todo o mundo, além de contribuir para as mudanças climáticas e ameaças a muitas espécies, diante disso, surge à necessidade da conservação de remanescente de vegetação nativa. Assim, existem áreas e espécies prioritárias para conservação, em especial na Caatinga, sendo considerada um importante reservatório de biodiversidade, por isso, vem recebendo uma atenção especial por parte da comunidade cientifica (Fonseca et al., 2017).

Na Caatinga, o modo de utilização dos recursos naturais é baseado no extrativismo, e as pressões antropogênicas são intensas, o que gera sérios problemas ambientais como: degradação dos solos, fragmentação da vegetação, além de submeter paulatinamente as espécies mais vulneráveis e/ou exploradas a processos de extinção (Pereira et al., 2001). No Brasil, existem aproximadamente 125 Unidades de Conservação registradas na região da Caatinga, considerando as unidades federais, estaduais, municipais e particulares, destas 15 se encontram no estado da Paraíba, contudo, tão importante quanto o número de UC existentes é sua abrangência, neste caso, as áreas nominalmente protegidas são pequenas em comparação com a respectiva extensão territorial (Gariglio et al., 2010).

No ecossistema Caatinga existe uma grande diversidade de espécies da flora, muitas delas preservadas nas unidades de conservação, e dentre elas temos Anadenanthera colubrina (Vell.) Brenan, conhecida popularmente como "angico", a qual apresenta ampla ocorrência no semiárido. Dependendo das condições físicas do ambiente, os indivíduos jovens apresentam muitos acúleos, as folhas são divididas em pequenos 
folíolos, sendo indicada como inseticida; e quando murchas, são altamente tóxicas. A exploração intensiva de sua madeira e casca pode comprometer a abundância da espécie (Rodrigues et al., 2007; Castro, 2010).

0 angico se encontra entre as espécies nativas do semiárido com prioridades de conservação, apesar de sua ampla ocorrência, e ser facilmente adaptada a diversos tipos de ambientes em vários países da América do Sul. 0 fator determinante é a grande demanda no mercado, pois esta espécie é utilizada para os mais diversos fins, desde planta ornamental, fornecedora de tanino, forrageira, energética, resinífera, madeireira até medicinal, sendo intensamente utilizadas suas cascas, folhas, madeiras e flores (Rodrigues et al., 2007).

Assim, são diversos os fatores que comprometem à conservação das espécies da flora na Caatinga, a maioria deles, proveniente de ações antropogênicas como extrativismo, desmatamento e queimadas. Através da utilização inadequada destes recursos os índices de degradação são elevados. Além disso, a inexistência de políticas públicas adequadas, falta de incentivos para reflorestamentos e fiscalização, são outros processos relacionados.

Diante desse contexto apresentado sobre o ecossistema Caatinga e a diversidade da flora presente nele, assim com as ameaças a sua conservação, a presente pesquisa objetivou registrar e avaliar a ocorrência e disponibilidade de Anadenanthera colubrina (Vell.) Brenan (angico) em oito comunidades rurais no semiárido da Paraíba. Esse estudo torna-se importante pois fornece informações interessantes sobre o contexto da distribuição do angico em várias regiões do semiárido, podendo ser utilizado em planos de manejo e conservação da flora da Caatinga.

\section{Material e métodos}

\section{Caracterização da área de estudo}

0 estudo foi realizado em oito municípios (Figura 1) no bioma Caatinga, distribuídos entre as mesorregiões do Agreste, Borborema e Sertão no estado da Paraíba, Nordeste do Brasil. Essas áreas apresentam déficit hídrico e alta evapotranspiração, onde o índice pluviométrico, em grande parte, é inferior a $800 \mathrm{~mm}$ anuais, a exemplo das áreas próximas a Depressão Sertaneja com média de $250 \mathrm{~mm}$ a $600 \mathrm{~mm}$ anuais (BNB, 2005).

Foram selecionadas duas comunidades rurais, respectivamente, nos Municípios de Solânea (Comunidade Capivara) e Remígio (Coelho), no Agreste paraibano; quatro na Borborema, nos Municípios de Cabaceiras (São Francisco), Congo (Santa Rita), São Mamede (Várzea Alegre) e Várzea (Pitombeira); e duas nos Municípios de Lagoa (Barroquinha) e Itaporanga (Pau d'Arco), no Sertão paraibano.

O Município de Remígio ( $06^{\circ} 54^{\prime} 10^{\prime \prime} \mathrm{S}$ e $35^{\circ} 50^{\prime} 02^{\prime \prime}$ ) ) localiza-se na Mesorregião do Agreste e Microrregião do Curimataú Ocidental. Seu território é de $178 \mathrm{~km}^{2}$, e sua população é de 18.922, o clima é do tipo Tropical Chuvoso, com verão seco (IBGE, 2010). A vegetação é formada por florestas subcaducifólia e caducifólia. A Comunidade Coelho, na zona rural deste município, localiza-se a oito quilômetros do centro urbano, sua economia predominante na agropecuária familiar, com destaque para a cultura do milho e feijão, e criação de caprinos, ovinos e bovinos.

O Município de Solânea $\left(06^{\circ} 46^{\prime} 40^{\prime \prime}\right.$ S e $35^{\circ} 04^{\prime} 49^{\prime \prime}$ 0) localiza-se na Mesorregião do Agreste e Microrregião do Curimataú Oriental, abrange uma área territorial de $232.094 \mathrm{~km}^{2}$, uma população de 26.925 , o clima é do tipo tropical chuvoso, com verão seco, a vegetação é formada por florestas subcaducifólia e caducifólia, típicas das áreas de agreste (IBGE, 2010). A Comunidade Capivara localiza-se, aproximadamente, $15 \mathrm{~km}$ da sede municipal, sua economia é a de subsistência, com destaque para a agricultura de sequeiro, cultivo de milho e feijão, na pecuária, destaca-se a criação de bovinos, caprinos e ovinos.

Rev. Bras. Gest. Amb. Sustent., 2020, vol. 7, n. 17, p. 1215-1229. 


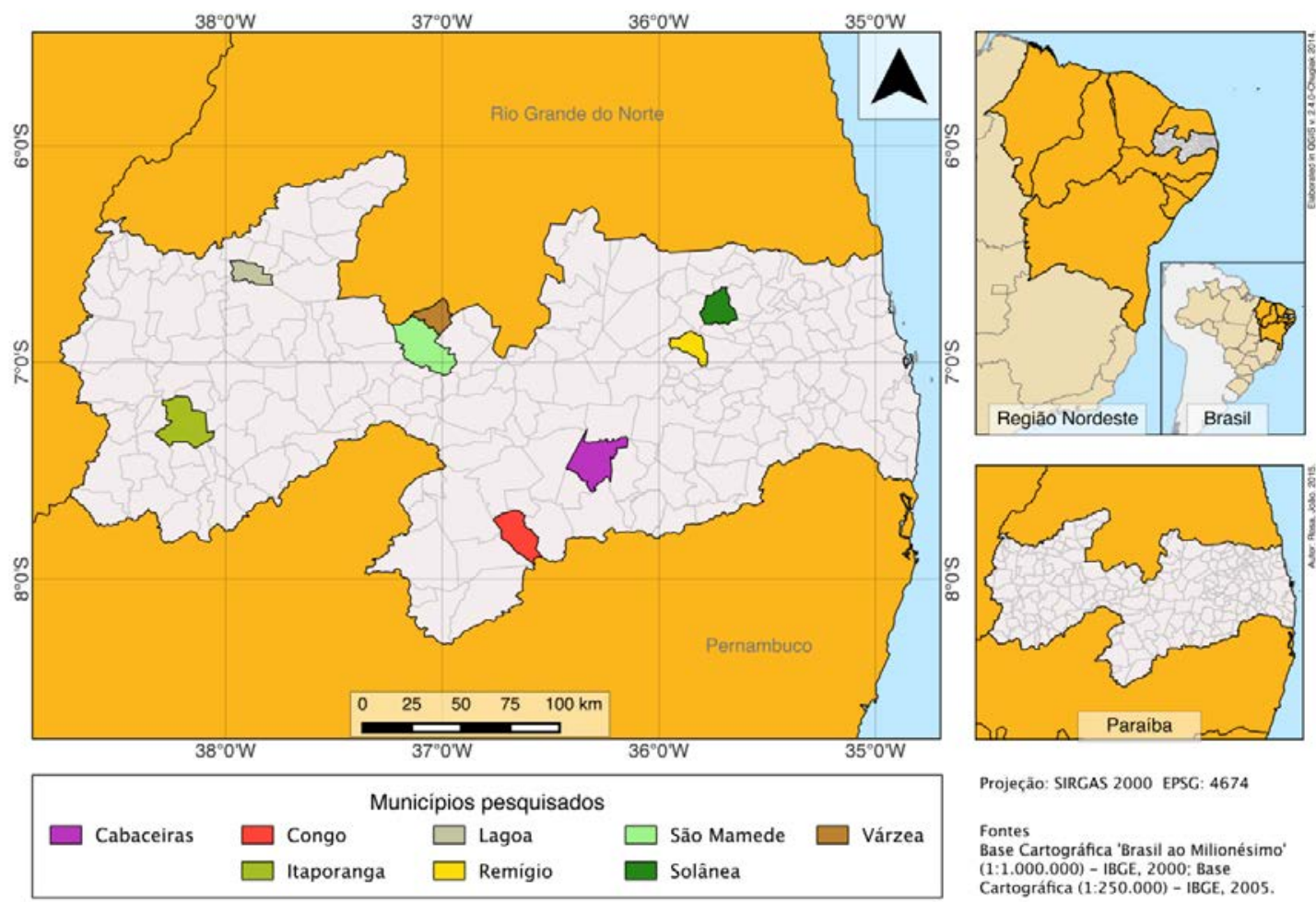

Figura 1. Localização geográfica dos municípios onde foi realizada a pesquisa, comunidades: São Francisco (Cabaceiras), Santa Rita (Congo), Pau d'Arco (Itaporanga), Barroquinha (Lagoa), Coelho (Remígio), Várzea Alegre (São Mamede), Capivara (Solânea), Pitombeira (Várzea) Estado da Paraíba, Nordeste do Brasil.

O Município de Cabaceiras ( $7^{\circ} 29^{\prime} 20^{\prime \prime} \mathrm{S}$ e $36^{\circ} 17^{\prime} 14^{\prime \prime}$ ) ), Microrregião do Cariri Oriental, tem área territorial equivalente a $452.920 \mathrm{~km}^{2}$, onde reside uma população de aproximadamente 5.386 (IBGE 2010). Possui clima semiárido quente (BSh), vegetação de caatinga, e chuvas irregulares. A Comunidade São Francisco está em uma área que vem sofrendo o processo de degradação, e na comunidade desenvolve-se atividades agropastoris de subsistência.

O Município do Congo ( $7^{\circ} 47^{\prime} 41^{\prime \prime} \mathrm{S}$ e $36^{\circ} 39^{\prime} 42^{\prime \prime} 0$ ), Microrregião do Cariri Ocidental, abrange uma área territorial de $333.469 \mathrm{~km}^{2}$, com uma população de 4.692 habitantes. Apresenta vegetação típica de Caatinga e clima semiárido quente (BSh) (IBGE, 2010). A Comunidade Santa Rita, localiza-se a oito km da sede município, sua economia local é baseada na agricultura de subsistência, culturas de milho e feijão, e pecuária com criação de caprinos, ovinos e bovinos.

O Município de São Mamede $\left(6^{\circ} 55^{\prime} 37^{\prime \prime} \mathrm{S}\right.$ e $\left.37^{\circ} 05^{\prime} 45^{\prime \prime} 0\right)$, localizado na Microrregião do Seridó Ocidental, tem uma população de 7.748, área territorial de $531 \mathrm{~km}^{2}$, a $253 \mathrm{~m}$ de altitude, apresenta clima semiárido quente (BSh), com temperatura média anual de $28^{\circ} \mathrm{C}$, vegetação típica de Caatinga (IBGE, 2010). A Comunidade Várzea Alegre se encontra a $8 \mathrm{~km}$ do centro urbano, a economia é voltada para o cultivo agrícola em períodos de chuva (milho e feijão), e desenvolvimento da pecuária (caprinos, ovinos e bovinos) com destaque para criação de bovino para a produção de leite.

O Município de Várzea ( $6^{\circ} 46^{\prime} 08^{\prime \prime}$ S e $36^{\circ} 59^{\prime} 02^{\prime \prime}$ ) encontra-se na Microrregião do Seridó Ocidental, com uma área territorial equivalente a $190.526 \mathrm{~km}^{2}$, população de 2.504 habitantes. 0 clima é do tipo semiárido quente (BSh), vegetação característica é do 
tipo Caatinga (IBGE, 2010). A Comunidade Pitombeira é constituída por pequenos produtores rurais que cultivam milho e feijão e criam caprinos, bovinos e ovinos, a renda dessas famílias é complementada por programas sociais do Governo Federal.

0 Município de Lagoa $\left(06^{\circ} 34^{\prime} 15^{\prime \prime} \mathrm{S}\right.$ e $37^{\circ} 54^{\prime} 57^{\prime \prime}$ 0) pertence à Microrregião de Catolé do Rocha, com uma população absoluta de 4.681, abrange uma área territorial de $177.901 \mathrm{~km}^{2}$, com clima semiárido quente (BSh) e vegetação típica do semiárido. A Comunidade Barroquinha apresenta práticas agropecuárias desenvolvidas por pequenos produtores rurais, com criação de ovinos, caprinos e ovinos, e cultivo de feijão, milho e fumo.

O Município de Itaporanga ( $7^{\circ} 18^{\prime} 14^{\prime \prime} \mathrm{S}$ e $38^{\circ} 09^{\prime} 00^{\prime \prime}$ ) ), localizado na Microrregião do Vale do Piancó, abrange uma área territorial de $468 \mathrm{~km}^{2}$, com uma população de 23.192, e o clima é semiárido quente (BSh), com uma curta estação chuvosa (IBGE, 2010). A economia baseia-se na agropecuária de pequenos produtores, com criações de pequenos e grandes ruminantes, cultivo de feijão e milho (MME, 2005). A Comunidade Pau d'Arco localiza-se, aproximadamente, a $8 \mathrm{~km}$ do centro urbano e apresenta economia voltada para a agropecuária de pequenos produtores rurais.

\section{Disponibilidade local}

Para caracterizar a ocorrência e disponibilidade local de A. colubrina foram realizados três métodos investigativos de levantamento da flora (Araújo e Ferraz, 2010). 0 primeiro foi o de parcelas (Figura 2), realizado nas Comunidades Várzea Alegre, Capivara, Pau d'Arco e Barroquinha; o segundo foi o de ponto quadrante (Figura 3) nas Comunidades Santa Rita e Coelho; o terceiro foi o caminhamento livre, nas Comunidades São Francisco, Santa Rita, Várzea Alegre e Pitombeira.

As comunidades rurais foram selecionadas por já existir estudos anteriores desenvolvidos nesses locais pelo Laboratório de Etnobiologia e Ciências Ambientais da Universidade Federal da Paraíba (Silva et al., 2018; Lima et al., 2016; Lucena et al., 2014; Carvalho et al., 2012; Coutinho et al., 2015; Guerra et al., 2015).

0 objetivo da realização da pesquisa não foi o de comparar diferentes métodos investigativos, mas de buscar registrar a disponibilidade local do angico nas comunidades estudadas, neste sentido, tanto o método de parcelas, quadrantes e caminhamento livre são importantes e complementares.

Em cada levantamento realizado foram registrados todos os indivíduos de angico com diâmetro de caule no nível do solo (DNS) igual ou superior a três centímetros, considerando os indivíduos vivos, além de registrar a ocorrência de extrativismo (Araújo e Ferraz, 2010). Na ficha de campo, para todos os indivíduos encontrados, foi anotado o perímetro com auxílio da fita métrica, altura com vara graduada, além de georreferenciamento com o GPS.

No primeiro segmento, método de parcelas, nas comunidades selecionadas foram plotadas parcelas em duas áreas distintas, sendo 50 parcelas para cada área. A primeira área foi alocada considerando uma área mais conservada (Área I), e a segunda em um ambiente mais antropizado, nomeado como área degradada (Área II). Foram plotadas

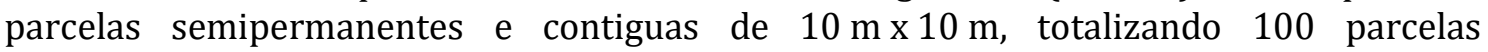
equivalentes a uma área total de 1,0 ha em cada comunidade (Araújo e Ferraz, 2010). Foram etiquetados todos os indivíduos e registrados altura e perímetro.

O segundo segmento da pesquisa, método de ponto quadrante, consistiu em formar uma cruz com dois pedaços de madeira, e sobrepor na superfície das áreas vegetais da comunidade estudada, do ponto que forma a cruz foram adotadas as distâncias dos indivíduos mais próximos, sendo amostrados quatro indivíduos para cada quadrante, onde se registrou o perímetro e altura de cada indivíduo (Araújo e Ferraz). Os quadrantes foram enumerados e os pontos foram lançados a cada $10 \mathrm{~m}$ em transectos de $100 \mathrm{~m}$, assim 
foram plotados 50 transectos em intervalos de $10 \mathrm{~m}$, totalizando 500 pontos para cada comunidade.

Por fim, o terceiro segmento, caminhamento livre, consistiu em localizar os indivíduos da espécie, a partir de caminhada livre em um período de $24 \mathrm{~h}$, percorrendo o perímetro físico de cada comunidade, em áreas de vegetação primária e secundária, estradas, áreas serranas, de cultivos, quintais agroflorestais e margem de rios. Cada indivíduo localizado foi georreferenciado, anotado perímetro e altura, além do registro de extrações de cascas quando ocorreram e observação da área de ocorrência, estes indivíduos foram marcados com tinta em spray para não correr o risco de um mesmo indivíduo ser identificado duas vezes.

O material vegetal do angico foi coletado com auxílio de tesoura de poda, herborizada em campo utilizando papelão, prensa e ficha de campo com nome vernacular e data da coleta. Em seguida, o material botânico coletado foi encaminhado ao laboratório para comprovação taxonômica, após sua identificação científica as exsicatas foram incorporadas ao acervo do Herbário Jaime Coelho de Moraes do Centro de Ciências Agrárias da Universidade Federal da Paraíba.

\section{Análises dos dados}

Os parâmetros fitossociológicos foram avaliados com o índices de valor de importância, densidade relativa, dominância relativa e frequência relativa (Castro et al., 1987; Rodal et al., 1992), em que a Densidade Relativa (DRt \%), foi medida pelo número de indivíduos de um determinado táxon com relação ao total de indivíduos amostrados; Frequência Relativa (FRt \%), foi estimada com base na FAt (Frequência total da espécie em questão), em relação à Frequência Total (FT \%), que representa o somatório de todas as frequências absolutas; A Dominância Relativa (DoR \%) representa a porcentagem de DoA (dominância absoluta da espécie) com relação a dominância total. Analisados através do Programa Fitopac, versão 2.0.

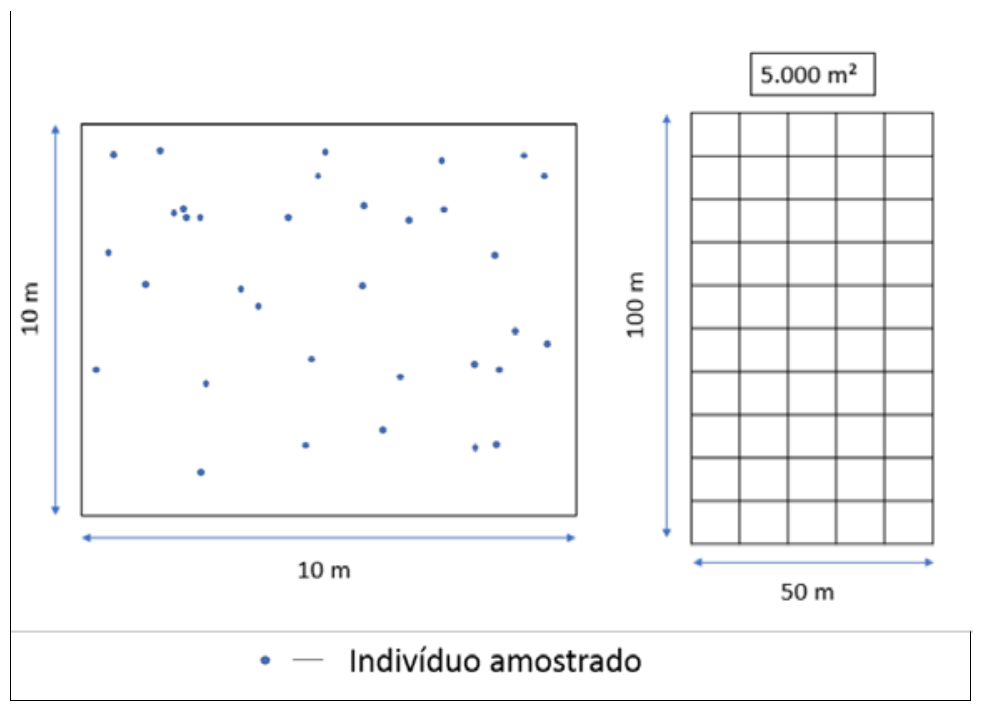

Figura 2. À esquerda, representação de uma parcela e suas dimensões; à direita representação do posicionamento e dimensões de 50 parcelas, demonstrando o padrão amostral para cada área. Fonte: Lucena et al. (2019). 

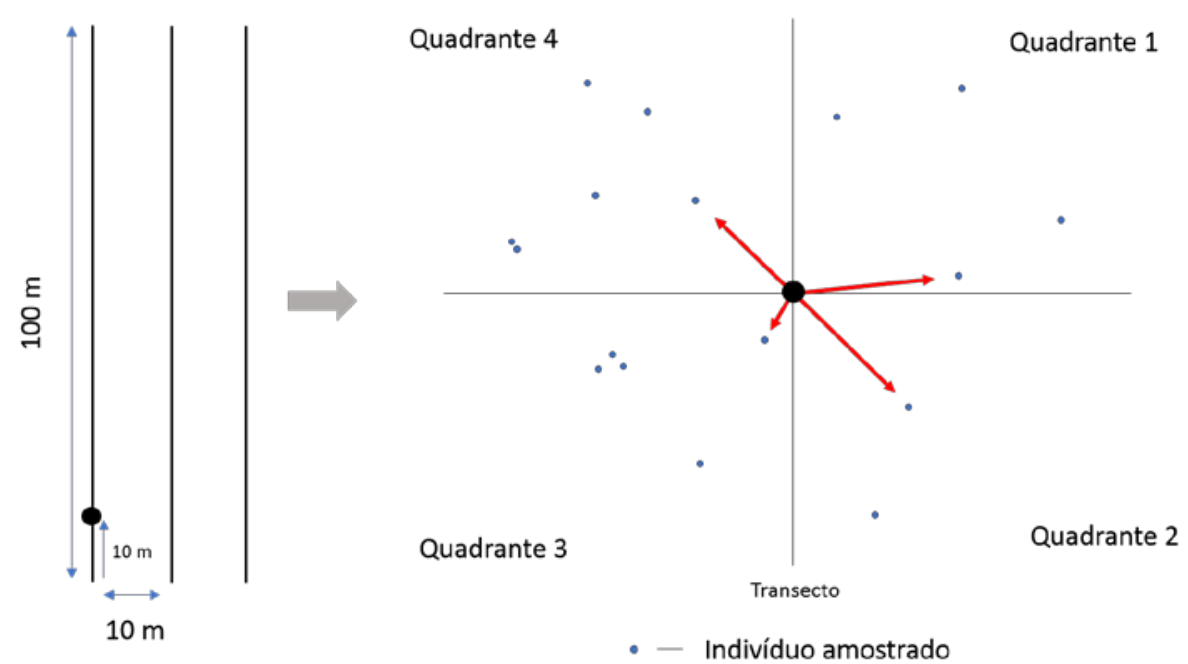

Figura 3. Representação das dimensões e estrutura dos transectos e pontos quadrantes. Fonte: adaptada de Trindade et al. (2015). Fonte: Lucena et al. (2019).

\section{Resultados}

\section{Disponibilidade local de Anadenanthera colubrina (Vell.) Brenan}

Nas comunidades pesquisadas onde se realizou o método de parcelas (Tabela 1), pode-se observar que não houve muita ocorrência da espécie, e para a comunidade Pau d'Arco não foi encontrado nenhum indivíduo. Para as demais comunidades se observou maior frequência relativa na área conservada (Área I) da comunidade Várzea Alegre.

Tabela 1. Parâmetros fitossociológicos de Anadenanthera colubrina (Vell.) Brenan, registrados em parcelas nas áreas conservadas (AI), degradadas (A II), área única (AU), nas comunidades rurais de Várzea Alegre (município de São Mamede), Capivara (Solânea), Pau d’Arco (Itaporanga), Barroquinha (Lagoa) e São Francisco (Cabaceiras) na Paraíba, nordeste do Brasil.

\begin{tabular}{|c|c|c|c|c|c|c|c|c|c|c|}
\hline \multirow{2}{*}{ Comunidades } & \multicolumn{2}{|c|}{ No Ind } & \multicolumn{2}{|c|}{ DeR\% } & \multicolumn{2}{|c|}{ FrR\% } & \multicolumn{2}{|c|}{ DoR\% } & \multicolumn{2}{|c|}{ VI } \\
\hline & AI & AII & AI & AII & AI & AII & AI & AII & AI & AII \\
\hline Várzea Alegre & 55 & - & 4,2 & - & 9,33 & - & 22,65 & - & 36,18 & - \\
\hline Capivara & - & 1 & - & 0,04 & - & 0,21 & - & 0,01 & - & 0,26 \\
\hline Pau d'Arco & - & - & - & - & - & - & - & - & - & - \\
\hline \multirow[t]{2}{*}{ Barroquinha } & 2 & 20 & 0,08 & 0,84 & 0,44 & 5,15 & 0,36 & 1,69 & 0,54 & 5,44 \\
\hline & \multicolumn{2}{|c|}{ UA } & \multicolumn{2}{|c|}{ UA } & \multicolumn{2}{|c|}{ UA } & \multicolumn{2}{|c|}{ UA } & \multicolumn{2}{|c|}{$\mathrm{AU}$} \\
\hline São Francisco & \multicolumn{2}{|c|}{8} & \multicolumn{2}{|c|}{0,24} & \multicolumn{2}{|c|}{1,7} & \multicolumn{2}{|c|}{1,83} & \multicolumn{2}{|c|}{3,77} \\
\hline
\end{tabular}

№ Ind = número de indivíduos, DeR = densidade relativa, $\mathrm{FrR}=$ frequência relativa, $\mathrm{DoR}=$ dominância relativa, VI = valor de importância.

Nas Comunidades Santa Rita (Município do Congo) e Coelho (Remígio), nas quais foi utilizado o método de pontos quadrantes (Tabela 2), observou-se indivíduos apenas na comunidade Santa Rita, com valores fitossociológicos relativamente significativos, haja vista que os valores de FrR e DoR foram superiores ao DeR, indicando que são indivíduos 
isolados e com número reduzido, contudo, distribuídos com certa regularidade na área. Por outro lado, na comunidade Coelho não foi possível identificar nenhum indivíduo nos 50 transectos distribuído na área estudada.

Tabela 2. Parâmetros fitossociológicos de Anadenanthera colubrina (Vell.) Brenan, resultantes de pontos quadrantes nas comunidades Santa Rita (município do Congo) e Coelho (Remígio) na Paraíba, nordeste do Brasil.

\begin{tabular}{|l|c|c|c|c|c|}
\hline Comunidades & No Ind & DeR\% & FrR\% & DoR\% & VI \\
\hline Santa Rita & 36 & 1,8 & 3,01 & 9,81 & 14,62 \\
\hline Coelho & - & - & - & - & - \\
\hline
\end{tabular}

№ Ind = número de indivíduos, DeR = densidade relativa, $\mathrm{FrR}$ = frequência relativa, $\mathrm{DoR}=$ dominância relativa, VI = valor de importância.

No método de caminhamento livre foram identificados indivíduos em todas as comunidades selecionadas, totalizando 694 nas quatro áreas pesquisadas, sendo registrados 181 indivíduos na comunidade São Francisco, 243 em Santa Rita, 214 em Várzea Alegre e 56 em Pitombeira.

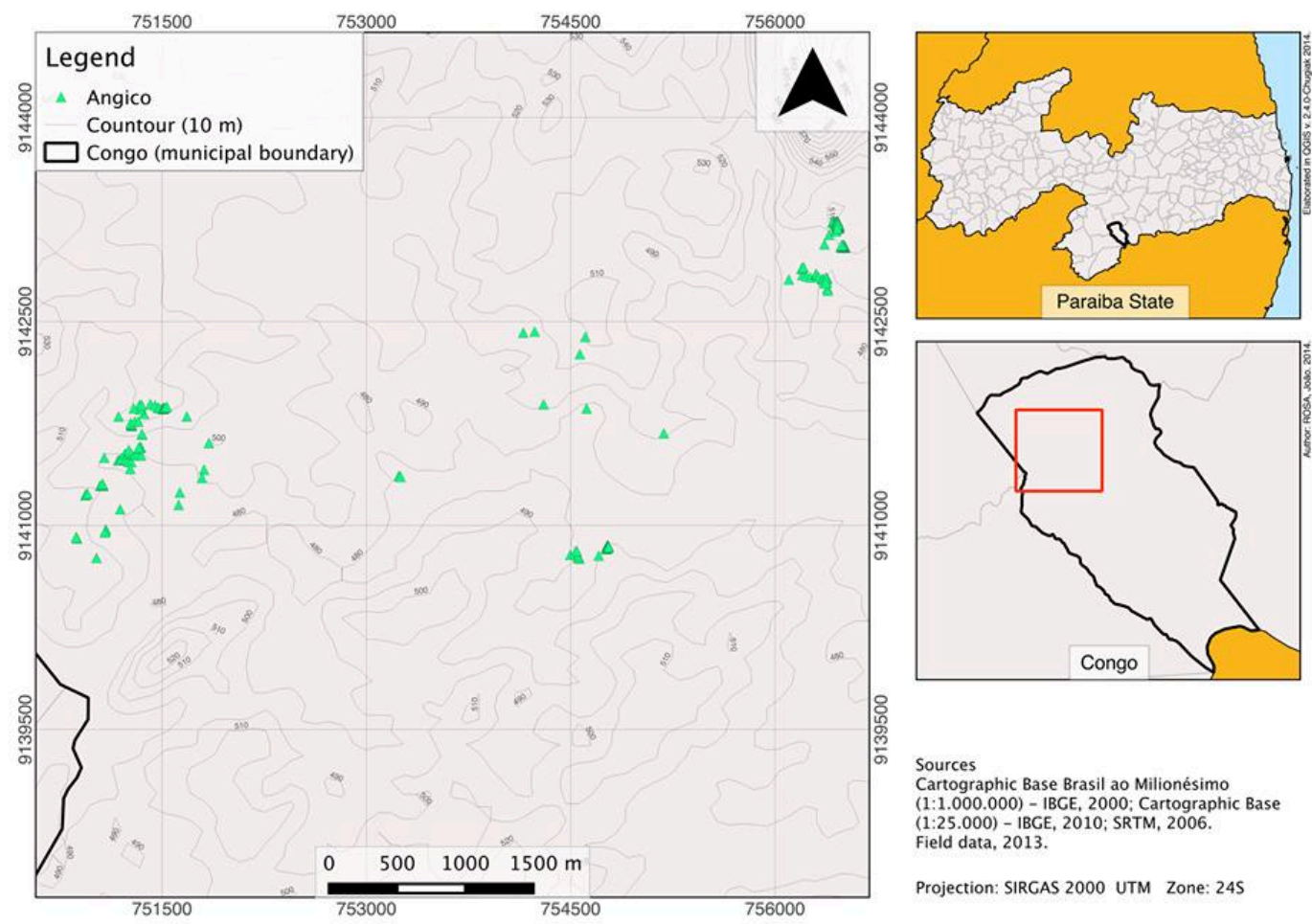

Figura 4. Distribuição espacial de Anadenanthera colubrina (Vell.) Brenan, resultante do método caminhamento livre realizado na comunidade Santa Rita, Congo, Paraíba, nordeste do Brasil. 
Na comunidade Santa Rita as populações de angico estão distribuídas muito próxima das casas (Figura 4), entre as casas e na área de serra. Por existir uma concentração de angico próximo às casas, este pode ser um indicador que estas populações rurais estão preservando a espécie. No caso da comunidade São Francisco (Figura 5) o maior número de casas da comunidade se encontra no centro, e as populações de angico nas áreas de vegetação nos extremos, o que pode indicar que as populações não mantêm o angico nas proximidades de suas residências por ser uma área mais antropizada destinada para cultivos agrícolas e pastagem.

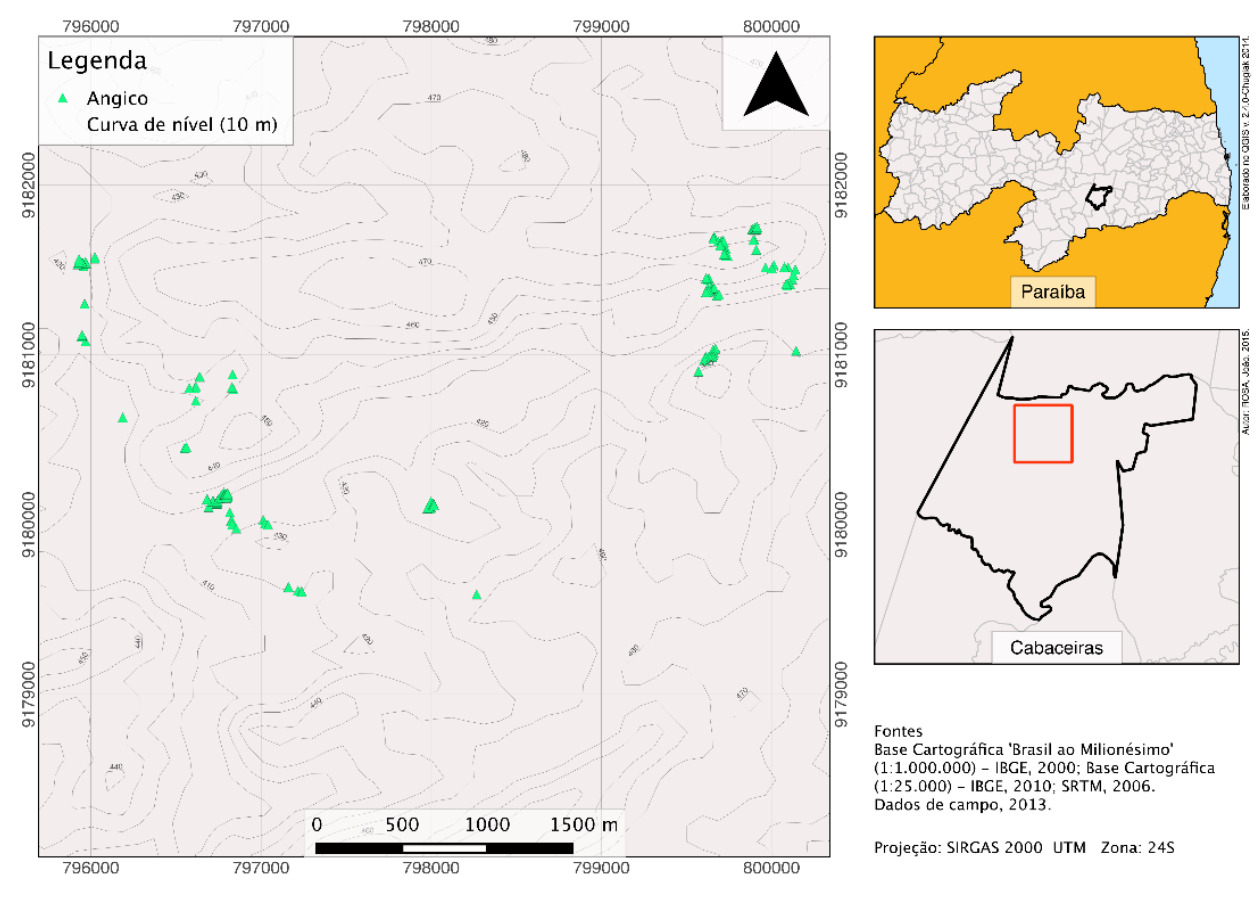

Figura 5. Distribuição espacial de Anadenanthera colubrina (Vell.) Brenan, resultante do método caminhamento livre realizado na comunidade São Francisco, Cabaceiras, Paraíba, nordeste do Brasil.

Para a comunidade Várzea Alegre (Figura 6) é perceptível que as populações da espécie estudada praticamente não existem próximas às residências rurais, com concentração na área de serra, local de mais difícil acesso e com vegetação densa. Já, na comunidade Pitombeira (Figura 7), as populações de angico remanescente se distribuem entre algumas residências e em áreas mais afastadas, contudo, na referida comunidade sua vegetação como um todo se encontra bastante antropizada, e o angico é uma das espécies utilizadas para fins madeireiros, o que pode explicar o baixo número de indivíduos georreferenciados. 

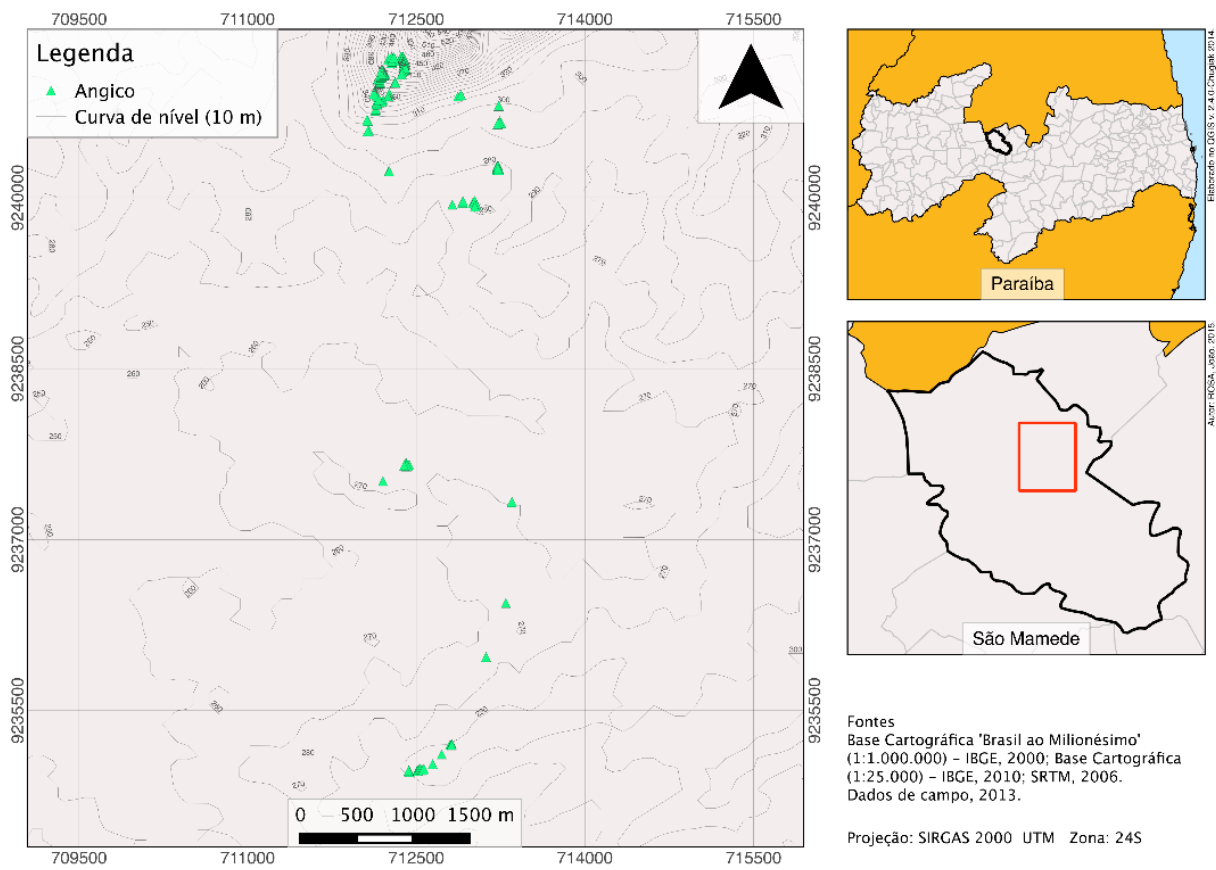

Base Cartográfica 'Brasil ao Milionésimo'

(1:1.000.000) - IBGE, 2000; Base Cartográfica

Dados de campo, 2013, SRTM, 2006.

Projeção: SIRCAS 2000 UTM Zona: $24 S$

Figura 6. Distribuição espacial de Anadenanthera colubrina (Vell.) Brenan, resultante do método caminhamento livre realizado na comunidade Várzea Alegre, São Mamede, Paraíba, nordeste do Brasil.
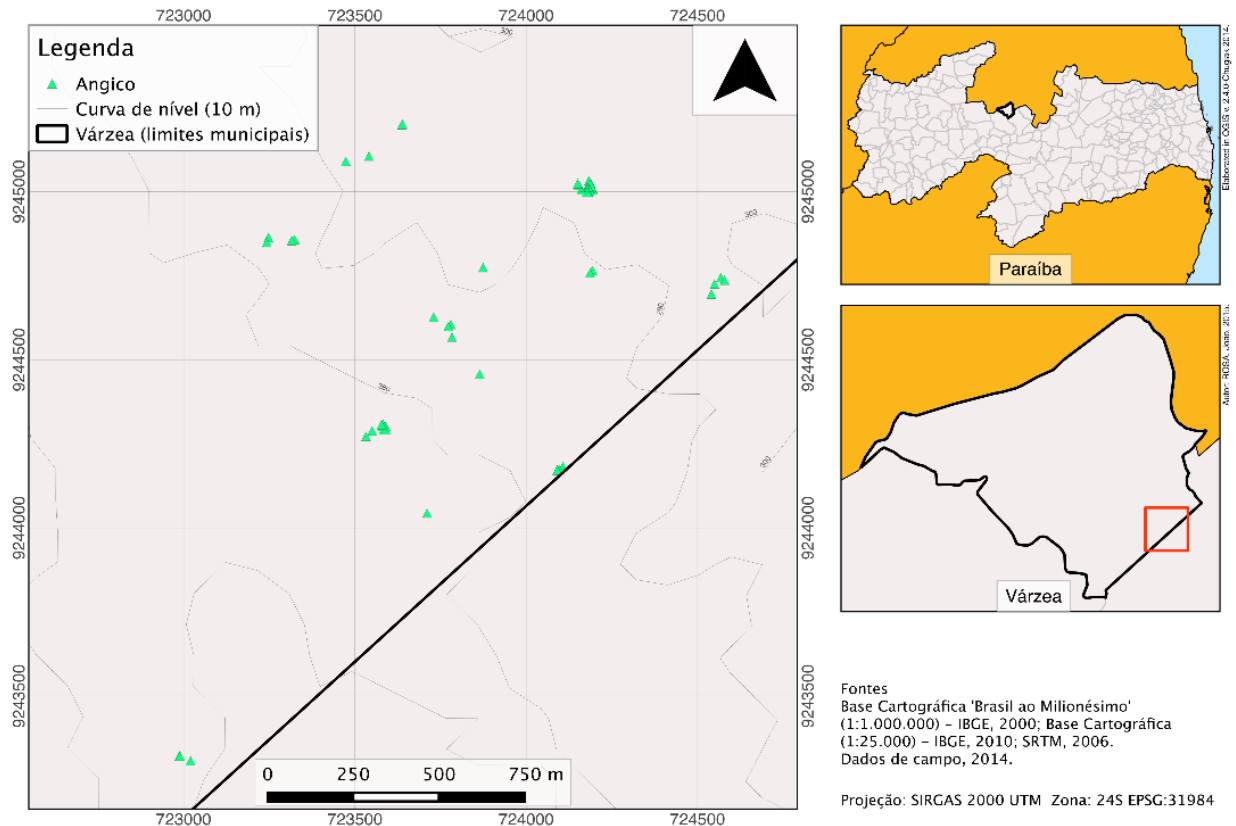

\section{Fontes}

Base Cartográfica 'Brasil ao Milionésimo' tográfica Dados de campo, 2014.

Projeçăo: SIRCAS 2000 UTM Zona: 24S EPSG:31984

Figura 7. Distribuição espacial de Anadenanthera colubrina (Vell.) Brenan, resultante do método caminhamento livre realizado nas comunidades Pitombeira e Várzea, Lagoa, Paraíba, nordeste do Brasil. 


\section{Discussão}

\section{Disponibilidade local de Anadenanthera colubrina (Vell.) Brenan}

Estudos fitossociológicos realizados em áreas de Caatinga contribuem para o conhecimento sobre a disponibilidade das espécies, assim como, a identificação de possíveis pressões de usos. Tendo em vista que tal ecossistema apresenta um considerável número de espécies vegetais ameaçadas de extinção ou com prioridade de conservação, por conseguinte, para a consolidação de práticas conservacionistas nestas áreas faz-se necessário o registro e identificação das espécies existentes.

A disponibilidade local do angico, em áreas de domínio de Caatinga, vem sendo registrada em outros estudos. A exemplo de Arruda et al. (2011), com estudos florísticos em fragmentos de floresta tropical seca no norte de Minas Gerais, bem como Ferraz et al. (2013) que realizou um estudo fitossociológico no estado de Sergipe, onde o angico se destacou dentre as espécies mais representativas de Fabaceae. Lucena et al. (2012a) com estudos sobre usos de recursos vegetais da Caatinga, no município de Soledade no estado da Paraíba, onde constataram números reduzidos de indivíduos para esta espécie.

Os registros fitossociológicos do angico nas comunidades estudadas obtidos a partir do método de parcelas demonstraram que a população desta espécie é pequena nestas referidas áreas. Na comunidade Várzea Alegre, foram registrados indivíduos apenas no fragmento conservado, e o que se pode perceber nesta comunidade é a heterogeneidade das áreas estudadas, resultante de um conjunto de fatores naturais e antrópicos. Em Barroquinha, foram encontrados indivíduos nos dois fragmentos vegetais. E na Comunidade São Francisco foram encontrados indivíduos apenas no fragmento de vegetação pertencente a esta comunidade.

Nas Comunidades Capivara e Pau d'Arco, os resultados encontrados para a espécie indicaram baixa densidade de indivíduos, haja vista que foi registrado apenas um indivíduo na primeira comunidade, enquanto nesta última não houve registros, o que implica dizer que a espécie está sendo ameaçada, e um dos problemas da Caatinga é justamente a acentuada redução da cobertura vegetal, a partir de práticas que resultam em impactos ao ambiente como um todo (Pereira et al., 2013). Para Costa et al. (2009) a modelagem da diversidade florística oriunda das pressões antropogênicas, bem como dos efeitos naturais que resultam em maior degradação biológica requerem intervenções apropriadas de recuperação.

Nas comunidades estudadas registraram-se os seguintes dados: densidade relativa (DeR) na comunidade Várzea Alegre foi de AI $(4,2)$; Capivara AII $(0,04)$; Barroquinha AI $(0,08)$ e AII $(0,84)$; comunidade São Francisco AU $(0,24)$. Para frequência relativa (FrR) os valores registrados foram: comunidade Várzea Alegre AI (9,33); comunidade Barroquinha AI $(0,44)$ e AII $(5,15)$; São Francisco AU $(1,70)$. Em pesquisas desenvolvidas por Guedes et al. (2012), em um trecho de Caatinga do semiárido paraibano na Reserva Legal da Fazenda Tamanduá, no município de Santa Terezinha, Paraíba, A. colubrina foi registrada com FrR igual a 6,84, valor superior ao encontrado nesta pesquisa.

Esses resultados demonstram a necessidade de estudos em escala regional para melhor compreender a dinâmica de distribuição do angico, assim como a sua disponibilidade e presença nas áreas florestais e antropizadas da Caatinga. Um fator que deve ser levado em consideração é a relação das populações humanas com essa espécie, o que pode ser uma das principais causas para a diferença encontrada na disponibilidade do angico nas diferentes comunidades estudadas.

Quanto a dominância relativa (DoR) em Várzea Alegre foi AI $(22,65)$; Barroquinha AI $(0,36)$ e AII $(1,69)$; São Francisco AU $(1,83)$. Pesquisas realizada por Ribeiro et al. (2013), em um fragmento de Caatinga no estado do Ceará registraram DoR de 2,56, valores próximos aos encontrados nesta pesquisa, exceto para a comunidade Várzea Alegre, estes autores afirmam ainda que a espécie apresenta alta prioridade de 
conservação local, precisando de restrição de usos e maior atenção nas ações conservacionistas.

Já o valor de importância (VI) do angico na comunidade Várzea Alegre foi AI $(36,18)$; Barroquinha AI $(0,87)$ e AII $(0,87)$; e São Francisco AU $(3,77)$. Resultados semelhantes foram registrados por Lucena et al., (2012), em uma pesquisa sobre recursos vegetais no município de Soledade na Paraíba, onde o número de angico foi inferior a dez indivíduos.

Com o método de ponto quadrante realizado nas Comunidades Santa Rita e Coelho, foi possível diagnosticar a presença do angico, apenas na primeira comunidade com 36 indivíduos, DeR (1,8), FrR $(3,01)$, DoR $(9,81)$ e VI $(14,62)$. Enquanto na comunidade Coelho (Remígio, Paraíba) não houve nenhum registro, contudo, a população residente e mencionou a referida espécie. A mesma pode ocorrer em áreas não inventariadas ou ter sido mencionada por estar na memória cultural da população.

Na distribuição local do angico por meio do método de caminhamento livre, foi possível registrar indivíduos no perímetro das comunidades, inclusive em áreas mais antropizadas, este fator pode ser um indicativo de preservação da espécie para fins medicinais, por exemplo, já que nos resultados se observa citações para esta categoria. Nas quatro comunidades estudadas foi registrado um total de 694 indivíduos. Resultados semelhantes foram encontrados por Pedrosa et al. (2012), que afirmaram ainda que este método além de ser abrangente, pode identificar extrações de cascas, através da indicação de moradores sobre a ocorrência da espécie.

\section{Conclusões}

A partir desta pesquisa pode-se relatar que existem poucos indivíduos de $A$. colubrina, inclusive nas comunidades Pau d'Arco e Coelho não foram identificados nenhum. Essa baixa presença registrada do angico nas áreas estudadas pode ser um indicativo de alta exploração local, e possível necessidade de ações conservacionista.

A maioria das populações locais possui o conhecimento da relação de uso e disponibilidade do angico, contudo é necessária uma atuação conjunta entre órgãos ambientes, pesquisadores e comunidade local visando o uso sustentável e a conservação da espécie.

\section{Conflito de interesses}

Os autores declaram não haver conflito de interesses.

\section{Referências}

Albuquerque, U. P.; Araujo, T. A. S.; Ramos, M. A.; Nascimento, V. T.; Lucena, R. F. P.; Monteiro, J. M.; Alencar, N.; Araújo, E. L. How ethnobotany can aid biodiversity conservation reflections on investigations in the semi-arid region of $\mathrm{NE}$ Brazil. Biodiversity and Conservation, v. 18, p.127-150, 2008. https://doi.org/10.1007/ s10531-008-9463-8

Almeida, C. F. C. B. R.; Albuquerque, U. P. Uso e conservação de plantas e animais medicinais no Estado de Pernambuco: um estudo de caso no Agreste. Interciência, v. 27, p. 276-285, 2002.

Araújo, E. L.; Ferraz, E. M. N. Análise da vegetação nos estudos etnobotânicos. In: Albuquerque, U. P.; Lucena, R. F. P.; Cunha, L. V. F. C. (Orgs). Métodos e técnicas na pesquisa etnobiológica e etnoecológica. Recife: NUPEEA, 2010. p. 223-253. 
Arruda, D. M.; Brandão, D. O.; Costa, F. V.; Tolentino, G. S.; Brasil, R. D.; D’Ângelo Neto, S.; Nunes, Y. R. F. Structural aspects and floristic similarity among tropical dry forest fragments with different management histories in Northern Minas Gerais, Brazil. Revista $\begin{array}{llll}\text { Árvore, } & \text { v. } 35, & \text { n. } 1, & \text { p. 131-142, 2011. https://doi.org/10.1590/S0100- }\end{array}$ 67622011000100016

BNB - Banco do Nordeste do Brasil. Proposta de dimensionamento do semi-árido brasileiro. Fortaleza: Banco do Nordeste do Brasil, 2005.

Carvalho, T. K. N.; Sousa, R. F.; Meneses, S. S. S.; Ribeiro, J. P. O.; Félix, L. P.; Lucena, R. F. P. Plantas usadas por uma comunidade rural na Depressão Sertaneja no Nordeste do Brasil. Biofar, v. especial, p. 92-120, 2012.

Castro, A. S. Flores da caatinga. Campina Grande: Instituto Nacional do Semiárido, 2010.

Costa, T. C. C.; Accioly, L. J. O.; Oliveira, L. M. T.; Oliveira, M. A. J.; Guimarães, D. P. Interação de fatores biofísicos e antrópicos com a diversidade florística na indicação de áreas para conservação do bioma Caatinga. Sociedade \& Natureza, v. 21, n. 1, p. 19-37, 2009.

Costa, T. C. C.; Oliveira, M. A. J.; Accioly, L. J. O.; Silva, F. H. B. B. Análise da degradação da Caatinga no Núcleo de Desertificação do Seridó (RN/PB). Revista Brasileira de Engenharia Agrícola e Ambiental, v. 13, Supl., p. 961-974, 2009. https://doi.org/ 10.1590/S1415-43662009000700020

Coutinho, P. C.; Soares, Z. A.; Ferreira, E. C.; Souza, D. V.; Oliveira, R. S.; Lucena, R. F. P. Knowledge and use of medicinal plants in the Semiarid Region of Brazil. Brazilian Journal of Biological Sciences, v. 2, n. 3, p. 51-74, 2015.

Dorneles, M. C.; Ranal, M. A.; Santana, D. G. Germinação de sementes e emergência de plântulas de Anadenanthera colubrina (Vell.) Brenan var. cebil (Griseb) Altschut, Fabaceae, estabelecida em fragmentos florestias do Cerrado, MG. Ciência Florestal, v. 23, n. 3, p. 291-304, 2013. https://doi.org/10.5902/1980509810541

Ferraz, R. C.; Mello, A. A.; Ferreira, R. A.; Prata, A. P. N. Levantamento fitossociológico em área de Caatinga no Monumento Natural Grota do Angico, Sergipe, Brasil. Revista Caatinga, v.26, n.3, p.89-98, 2013.

Fonseca, C. R.; Antongiovani, M.; Matsumoto, M.; Bernard, E.; Venticinque E. M. The Caatinga: Understanding the challenges. In: Silva, J. M. C.; Leal, I. R.; Tabarelli, M. (Orgs.). Caatinga: The largest tropical dry forest region in South America. Gewerbestrasse: Springer, 2017. p. 429-443. https://doi.org/10.1007/978-3-319-68339-3_1

Francisco, P. R. M.; Chaves, I. B.; Chaves, L. H. G.; Lima, E. R. V. Estimativa da degradação da biomassa da vegetação de Caatinga através de índices de vegetação. Polêm!ca, v. 12, n. 2, p. 306-321, 2013.

Gariglio, M. A. (Org.). Uso sustentável e conservação dos recursos florestais da Caatinga. Brasília: Serviço Florestal Brasileiro 2010.

Gomes, T. B.; Bandeira, F. P. S. F. Uso e diversidade de plantas medicinais em uma comunidade quilombola no Raso da Catarina, Bahia. Acta Botanica Brasilica, v. 26, n. 4, p. 796-809, 2012. https://doi.org/10.1590/S0102-33062012000400009

Guedes, R. S.; Zanella, F. C. V.; Costa Júnior, J. E. V.; Santana, G. M.; Silva, J. A. Caracterização florístico-fitossociológico do componente lenhoso de um trecho de Caatinga no semiárido paraibano. Revista Caatinga, v. 25, n. 2, p. 99-108, 2012. 
Guerra, N. M.; Carvalho, T. K. N.; Ribeiro, J. S.; Ribeiro, J. P. O.; Barbosa, A. R.; Lima, J. R. F.; Alves, C. A. B.; Oliveira, R. S.; Lucena, R. F. P. Ecological apparency hypothesis and plant utility in the Semiarid Region of Brazil. Ethnobotany Research \& Applications, v. 14, p. 423-435, 2015.

IBGE - Instituto Brasileiro de Geografia e Estatística. Rio de Janeiro. 2004. Disponível em: <http://www.ibge.gov.br>. Acesso em: 10 abr. 2020.

Lima, J. R. F.; Alves, C. A. B.; Ribeiro, J. E. S.; Cruz, D. D.; Mourão, J. S.; Torre Cuadros, M. A.; Lucena, R. F. P. Uso e disponibilidade de espécies vegetais nativas no semiárido do Nordeste do Brasil: uma análise da hipótese da aparência ecológica. REDE - Revista Eletrônica do PRODEMA, v. 10, n. 1, p. 110-131, 2016.

Lucena, R. F. P. Avaliando a diferença de diferentes técnicas de coleta e análise de dados para a conservação da biodiversidade a partir do conhecimento local. Recife: Universidade Federal Rural de Pernambuco, 2009. (Tese de doutorado).

Lucena, R. F. P.; Leite, A. P.; Pedrosa, K. M.; Lucena, C. M.; Vasconcelos Neto, C. F. A.; Ribeiro, J. P. O. O uso de espécies vegetais no Vale do Piancó pode ser explicado por sua disponibilidade local? Biofar, v. especial, p. 55-71, 2012 c.

Lucena, R. F. P.; Medeiros, P. M.; Araujo, E. F.; Alves, A. G. C.; Albuquerque, U. P. The ecological apparency hypothesis and the importance of useful plants in rural communities from Northeastern Brazil: An assessment based on use value. Journal of Environmental Management, v. 96, p. 106-115, 2012b. https://doi.org/10.1016/j.jenvman.2011.09.001

Lucena, R. F. P.; Soares, T. C.; Vasconcelos Neto, C. F. A.; Carvalho, T. K. N.; Lucena, C. M.; Alves, R. R. N. Uso de recursos vegetais da Caatinga em uma comunidade rural no Curimataú Paraibano (Nordeste do Brasil). Revista Polibotânica, v. 34, p. 217-238, 2012a.

Lucena, R. F. P.; Sousa, R. F.; Guerra, N. M.; Ribeiro, J. E. S.; Leite, A. P.; Abreu, D. B. O.; Carvalho, T. K. N.; Trovão, D. M. B. M.; Alves, C. A. B.; Alves, R. R. N.; Borges, P. F.; Andrade, L. A.; Souto, J. S.; Sousa Júnior, S. P. S.; Nunes, E. N. The ecological apparency hypothesis and dry tropical forests: An ethnobotanical assessment. Etnoecológica, v. 10, n. 9, p. 1-17, 2014.

MME - Ministério de Minas e Energia. Projeto cadastro de fontes de abastecimento por água subterrânea: Paraíba. Brasília: MME, 2005.

Pedrosa, K. M.; Gomes, D. S.; Lucena, C. M.; Pereira, D. D.; Silviano, G. S.; Lucena, R. F. P. Uso e disponibilidade local de Sideroxylon obtusifolium (Roem. \& Schult.) T.D. Penn. (quixabeira) em três regiões da Depressão Sertaneja da Paraíba, Nordeste do Brasil. Biofar, v. Especial, p. 158-183, 2012.

Pegado, C. M. A. Efeitos da invasão biológica de algaroba: Prosopis Juliflora (SW) DC. sobre a decomposição e a estrutura do estrato arbustivo-arbório da Caatinga no Município de Monteiro, PB, Brasil. Acta Botanica Brasilica, v. 20, n. 4, p. 887-898, 2006. https://doi.org/10.1590/S0102-33062006000400013

Pereira, R. A.; Alcântara, C. R.; Dantas Neto, J.; Barbosa, E. M. Análise espaço-temporal da cobertura vegetal e do avanço de Prosopis juliflora (SW) DC numa área de Caatinga. RA'E GA, v. 28, p. 154-180, 2013. https://doi.org/10.5380/raega.v28i0.32305

Pereira, R. C. A.; Lima, M. J. A.; Du Bocage-Neta, A. L. Vegetação e flora de uma área de caatinga nos Cariris Velhos (semi-árido nordestino), Brasil. Pesquisa Agropecuária Pernambucana, v. 12, n. especial, p. 11-17, 2001. 
Ribeiro, D. A.; Macêdo, M. S.; Araújo, T. M. S.; Silva, M. A. P.; Lacerda, S. R.; Souza, M. M. A. Prioridade de conservação para espécies medicinais lenhosas em uma área de Caatinga, Assaré, Ceará, Brasil. Caderno de Cultura e Ciência, v. 12, n. 1, p. 46-57, 2013.

Rodrigues, A. C. C.; Osuna, J. T. A.; Queiroz, S. R. O. D.; Rios, A. P. S. Efeito do substrato e luminosidade na germinação de Anadenanthera colubrina (Fabaceae, Mimosoideae). Revista Árvore, v. 31, n. 2, p.187-193, 2007. https://doi.org/10.1590/S010067622007000200001

Silva, A. A, S.; Santos, S. S.; Ferreira, E. C.; Carvalho, T. K. N.; Lucena, C. M.; Nunes, G. M.; Madruga Filho, V. J. P.; Lucena, R. F. P. Utilização de plantas na veterinária popular no Semiárido da Paraíba, Nordeste do Brasil. FLOVET, v. 1, n. 10, p. 37-60, 2018.

Silva, J. M.; Martins, G. M. C.; Silva, H. C. H.; Moura, F. B. P. Conhecimento Ecológico tradicional e extrativismo do angico-de-caroço no Semiárido Alagoano. Revista Ouricuri, v. 4, n. 2, p 97-114, 2014b.

Silva, N.; Lucena, R. F. P.; Lima, J. R. F.; Lima, G. D. S.; Carvalho, T. K. N.; Sousa Júnior, S. P.; Alves, C. A. B. Conhecimento e uso da vegetação nativa da Caatinga em uma comunidade rural da Paraíba, Nordeste do Brasil. Boletim do Museu de Biologia Mello Leitão, Nova Série, v. 34, p. 5-37, 2014a.

Siqueira, A. S.; Araújo, G. M.; Schiavini, I. Estrutura do comportamento arbóreo e características edáficas de dois fragmentos de floresta estacional decidual no Vale do Rio Araguari, MG, Brasil. Acta Botanica Brasilica, v. 23, n. 1, p. 10-20, 2009. https://doi.org/ 10.1590/S0102-33062009000100003

Soares, Z. A.; Lucena, R. F. P.; Ribeiro, J. E. S.; Carvalho, T. K. N.; Ribeiro, J. P. O.; Guerra, N. M.; Silva, N.; Pedrosa, K. M.; Coutinho, P. C.; Lucena, C. M.; Alves, C. A. B.; Sousa Júnior, S. P. Local botanical knowledge about useful species in a semi-arid region from Northeastern Brazil. Gaia Scientia, v. 7, n. 1, p. 80-103, 2014.

Informação da Licença: Este é um artigo Open Access distribuído sob os termos da Licença Creative Commons Attribution, que permite uso irrestrito, distribuição e reprodução em qualquer meio, desde que a obra original seja devidamente citada. 